\title{
Combining Bottom-Up and Top-Down
}

\author{
Christoph Böhringer \\ Department of Economics, University of Oldenburg \\ Centre for European Economic Research (ZEW), Mannheim \\ BOEHRINGER@UNI-OLDENBURG.DE
}

Thomas F. Rutherford

Ann Arbor, Michigan

TOM@MPSGE.ORG

Revised March, 2007

\begin{abstract}
We motivate the formulation of market equilibrium as a mixed complementarity problem which explicitly represents weak inequalities and complementarity between decision variables and equilibrium conditions. The complementarity format permits an energy-economy model to combine technological detail of a bottom-up energy system with a second-best characterization of the overall economy. Our primary objective is pedagogic. We first lay out the complementarity features of economic equilibrium and demonstrate how we can integrate bottom-up activity analysis into a top-down representation of the broader economy. We then provide a stylized numerical example of an integrated model - within both static and dynamic settings. Finally, we present illustrative applications to three themes figuring prominently on the energy policy agenda of many industrialized countries: nuclear phase-out, green quotas, and environmental tax reforms.
\end{abstract}

JEL classification: C61, C68, D58, Q43

Keywords: Computable General Equilibrium, Complementarity, Bottom-Up, Top-Down

\section{Introduction}

There are two wide-spread modeling approaches for the quantitative assessment of economic impacts induced by energy policies: bottom-up models of the energy system and top-down models of the 
broader economy. The two model classes differ mainly with respect to the emphasis placed on technological details of the energy system vis-à-vis the comprehensiveness of endogenous market adjustments.

Bottom-up energy system models are partial equilibrium representations of the energy sector. They feature a large number of discrete energy technologies to capture substitution of energy carriers on the primary and final energy level, process substitution, or efficiency improvements. Such models often neglect the macroeconomic impact of energy policies. Bottom-up energy system models are typically cast as optimization problems which compute the least-cost combination of energy system activities to meet a given demand for final energy or energy services subject to technical restrictions and energy policy constraints.

Top-down models adopt an economy-wide perspective taking into account initial market distortions, pecuniary spillovers, and income effects for various economic agents such as households or government. Endogeneity in economic responses to policy shocks typically comes at the expense of specific sectoral or technological details. Conventional top-down models of energy-economy interactions have a limited representation of the energy system. Energy transformation processes are characterized by smooth production functions which capture local substitution (transformation) possibilities through constant elasticities of substitution (transformation). As a consequence, topdown models usually lack detail on current and future technological options which may be relevant for an appropriate assessment of energy policy proposals. In addition, top-down models may not assure fundamental physical restrictions such as the conservation of matter and energy.

The specific strengths and weaknesses of the bottom-up and top-down approaches explain the wide range of hybrid modeling efforts that combine technological explicitness of bottom-up models with the economic comprehensiveness of top-down models (see Hourcade, Jaccard, Bataille and Gershi (2006)). These efforts may be distinguished into three broader categories: First, independently developed bottom-up and top-down models can be linked. This approach has been adopted since the early 1970's, but it often challenges overall coherence due to inconsistencies in behavioral assumptions and accounting concepts across "soft-linked" models. ${ }^{1}$ Second, one could focus on one model type - either bottom-up or top-down - and use "reduced form" representations of the other. Prominent examples include ETA-Macro (Manne (1977)) and its successor MERGE (Manne, Mendelsohn and Richels (2006)) which link a bottom-up energy system model with a highly aggregate one-sector macro-economic model of production and consumption within a single optimization framework. Recent hybrid modelling approaches based on the same technique are described in Bahn, Kypreos, Büeler and Luethi (1999), Messner and Schrattenholzer (2000), or Bosetti, Carraro, Galeotti, Massetti and Tavoni (2006). The third approach provides completely integrated models based on developments of solution algorithms for mixed complementarity problems during

\footnotetext{
${ }^{1}$ See e.g. Hofman and Jorgenson (1976), Hogan and Weyant (1982), Messner and Strubegger (1987), Drouet, Haurie, Labriet, Thalmann, Vielle and Viguier (2005), or Schäfer and Jacoby (2006)
} 
the 1990's (Dirkse and Ferris (1995), Rutherford (1995)). In an earlier paper, Böhringer (1998) stresses the difference between bottom-up and top-down with respect to the characterization of technology options and associated input substitution possibilities in production. More lately, Schumacher and Sands (2006) investigate process shifts and changes in the fuel input structure for the steel industry comparing an aggregate top-down production characterisation with a bottom-up description of technologies for producing iron and steel. Both papers highlight the importance of "true" technology-based activity analysis in evaluating policy-induced structural change at the sectoral level.

In this paper, we focus on the third approach to hybrid modeling, i.e. the direct combination of bottom-up and top-down in a complementarity format. Our primary objective is pedagogic. We show that complementarity is a feature of economic equilibrium rather than an equilibrium condition per se. Complementarity can then be exploited to cast an economic equilibrium as a mixed complementarity problem. The complementarity format facilitates weak inequalities and logical connections between prices and market conditions. These properties permit the modeler to integrate bottom-up activity analysis directly within a top-down representation of the broader economy. Apart from accommodating technological explicitness in an economy-wide framework, the mixed complementarity approach relaxes so-called integrability conditions that are inherent to economic models formulated as optimization problem (see Pressman (1970) or Takayma and Judge (1971)). First-order conditions from primal or dual mathematical programs impose efficient allocation which rules out common second-best phenomena. Since many policy issues are associated with second-best characteristics of the real world - such as initial tax distortions or market failures - the optimization approach to integrate bottom-up and top-down is limited in the scope of policy applications. Non-integrabilities furthermore reflect empirical evidence that individual demand functions depend not only on prices but also on factor incomes. In such cases, demand functions are typically not integrable into an economy-wide utility function (see e.g.Rutherford (1999b)) and income effects matter (Hurwicz (1999) or Russell (1999)). ${ }^{2}$

Given the coherence and comprehensiveness of the complementarity format, we want to demonstrate how this approach can be implemented for applied energy policy analysis. In section 2, we provide a formal exposition of the complementarity features of economic equilibria and illustrate the direct integration of bottom-up energy system activity analysis into top-down economic modeling. In section 3, we develop a stylized numerical example of a hybrid bottom-up /top-down model - within both static and dynamic settings. In section 4, we illustrate application of this type of model by considering three prominent themes on the energy policy agenda of many industrialized countries: nuclear phase-out, green quotas, and environmental tax reforms. In section 5, we conclude. Our paper documents algebraic structure and data inputs to the simulations reported

\footnotetext{
${ }^{2}$ Only if the matrix of cross-price elasticities, i.e. the first-order partial derivatives of the demand functions, is symmetric, is there an associated optimization problem which can be used to compute the equilibrium prices and quantities.
} 
herein. The interested reader can download the computer programs to replicate our results from http://www.mpsge.org/td-bu.zip. ${ }^{3}$

\section{Complementarity and Arrow-Debreu Equilibria}

We consider a competitive economy with $n$ commodities (including primary factors), $m$ production activities (sectors), and $h$ households. The decision variables of the economy can be classified into three categories (Mathiesen (1985)):

$p \quad$ is a non-negative $n$-vector (with running index $i$ ) in prices for all goods and factors,

$y \quad$ denotes a non-negative $m$-vector (with running index $j$ ) for activity levels of constant-returns-to-scale (CRTS) production sectors, and

$M \quad$ represents a non-negative $k$-vector (with running index $h$ ) in incomes.

A competitive market equilibrium is characterized by a vector of activity levels $(y \geq 0)$, a vector of prices $(p \geq 0)$, and a vector of incomes $(M)$ such that:

- Zero profit implies that no production activity makes a positive profit, i.e.:

$$
-\Pi_{j}(p) \geq 0
$$

where:

$\Pi_{j}(p)$ denotes the unit-profit function for CRTS production activity $j$, which is calculated as the difference between unit revenue and unit cost. ${ }^{4}$

- Market clearance requires that supply minus demand is non-negative for all goods and factors, i.e.:

$$
\sum_{j} y_{j} \frac{\partial \Pi_{j}(p)}{\partial p_{i}}+\sum_{h} w_{i h} \geq \sum_{h} d_{i h}\left(p, M_{h}\right) \quad \forall i
$$

where:

$$
\begin{aligned}
& w_{\text {ih }} \quad \text { indicates the initial endowment matrix by commodity andhousehold), } \\
& \frac{\partial \Pi_{j}(p)}{\partial p_{i}} \quad \text { is (by Hotelling's lemma) the compensated supply of good } i \text { per unit operation } \\
& \text { of activity } j \text {, and } \\
& d_{i h}\left(p, M_{h}\right) \text { is the utility maximizing demand for good } i \text { by household } h \text {. }
\end{aligned}
$$

\footnotetext{
${ }^{3}$ We have implemented our models using GAMS/MCP (see Brooke, Kendrick and Meeraus (1996) and Rutherford (1995)) as well as GAMS/MPSGE (Rutherford 1999a) using the PATH solver (Dirkse and Ferris 1995).

${ }^{4}$ Technologies are assumed to exhibit constant returns to scale, hence the unit-profit function is homogeneous of degree one in prices, and by Euler's theorem $\Pi_{j}=\sum_{i} p_{i} \frac{\partial \Pi_{j}(p)}{\partial p_{i}}$.
} 
- Expenditure for each household $h$ equals factor income, i.e.:

$$
M_{h}=\sum_{i} p_{i} w_{i h}
$$

An economic equilibrium consists of inequalities (1) and (2), equations (3), ${ }^{5}$ and two additional conditions:

- Irreversibility: all activities are operated at non-negative levels:

$$
y_{j} \geq 0 \quad \forall j
$$

- Free disposal: prices remain non-negative:

$$
p_{i} \geq 0 \quad \forall i
$$

Provided that underlying utility functions exhibit non-satiation, household expenditure will exhaust income, hence:

$$
\sum_{i} p_{i} d_{i h}\left(p, M_{h}\right)-M_{h}=\sum_{i} p_{i} w_{i h}
$$

Substituting $p^{T}\left(d_{h}\left(p, M_{h}\right)-w_{h}\right)=0$ into (2) produces the inequality:

$$
\sum_{i} p_{i} y_{j} \frac{\partial \Pi_{j}}{\partial p_{i}}=y_{j} \Pi_{j}(p) \geq 0 \quad \forall j
$$

Equations (4) and (1) conversely imply that $y_{j} \Pi_{j}(p) \leq 0 \forall j$. Hence, we can infer that in equilibrium, any activity which earns negative unit profits is idle:

$$
y_{j} \Pi_{j}(p)=0 \quad \forall j,
$$

and any commodity in excess supply must have a zero price:

$$
p_{i}\left[\sum_{j} a_{i j}(p) y_{j}+\sum_{h} w_{i h}-\sum_{h} d_{i h}\left(p, M_{h}\right)\right]=0 \quad \forall i .
$$

We thus conclude that complementarity is a characteristic rather than a condition for equilibrium in the Arrow-Debreu model. This characteristic of the equilibrium allocation motivates formulation of economic models in a mixed complementarity format. The approach further permits direct integration of bottom-up activity analysis in which alternative technologies may produce

\footnotetext{
${ }^{5}$ The income vector is introduced as a vector of intermediate variables which simplify implementation. These may be substituted out of the model without altering the basic logic (as in Mathiesen (1985)).
} 
one or more products subject to process-oriented capacity constraints. As a canonical example, we may consider the energy sector linear programming problem which seeks to find the least-cost schedule for meeting an exogenous set of energy demands using a given set of energy technologies, $t$ :

$$
\min \sum_{t} \bar{c}_{t} y_{t}
$$

subject to

$$
\begin{gathered}
\sum_{t} a_{j t} y_{t}=\bar{d}_{j} \quad \forall j \in\{\text { energy goods }\} \\
\sum_{t} b_{k t} y_{t} \leq \kappa_{k} \quad \forall k \in\{\text { energy resources }\} \\
y_{t} \geq 0
\end{gathered}
$$

where:

$y_{t}$ is the activity level of energy technology $t$,

$a_{j t}$ denotes the netput of energy good $j$ by technology $t$ (energy goods may be either inputs or outputs),

$\bar{c}_{t} \quad$ is the exogenous marginal cost of technology $t$,

$\bar{d}_{j} \quad$ represents market demand for energy good $j$,

$b_{k t} \quad$ represents the unit demand for energy resource $k$ by technology $t$, and

$\kappa_{k}$ is the aggregate supply of energy resource, $k$. Such resources may include generation, pipeline or transmission capacities, some of which may be specific to an individual technology and others which may be traded in markets and thus transferred to most efficient use.

We write bars over $c_{t}$ and $d_{j}$ indicating that while these parameters are taken as given from the standpoint of firms in the energy sector, their values are determined as part of the outer economic equilibrium model.

When we derive the Kuhn-Tucker conditions characterize optimality of this linear program, we obtain:

$$
\sum_{t} a_{j t} y_{t}=\bar{d}_{j}, \quad \pi_{j} \geq 0, \quad \pi_{j}\left(\sum_{t} a_{j t} y_{t}=\bar{d}_{j}\right)=0
$$

and

$$
\sum_{t} b_{i t} y_{t} \leq \kappa_{i}, \quad \mu_{i} \geq 0, \quad \mu_{i}\left(\sum_{t} b_{i t} y_{t} \leq \kappa_{i}\right)=0
$$

where: 
$\pi_{j}$ is the Lagrange multiplier on the price-demand balance for energy good $j$, and

$\mu_{i} \quad$ is the shadow price on the energy sector resource $i$.

Comparing the Kuhn-Tucker conditions with our market equilibrium model, we note an equivalence between the shadow prices of mathematical programming constraints and market prices. The mathematical program can be interpreted as a special case of the general equilibrium problem where (i) income constraints are dropped, (ii) energy demands are exogenous, and (iii) energy supply technologies are characterized by fixed as opposed to price-responsive coefficients. In turn, we can replace an aggregate top-down description of energy good production in the general equilibrium setting by the Kuhn-Tucker conditions of the linear program, thereby providing technological details while treating all prices as endogenous.

The weak duality theorem relates the optimal value of the linear program to shadow prices and constants appearing in the constraint equations:

$$
\sum_{j} \pi_{j} \bar{d}_{j}=\sum_{t} c_{t} y_{t}+\sum_{k} \mu_{k} \kappa_{k}
$$

Equation (9) provides one further insight into the relationship of the bottom-up linear programming model and the outer economic environment. It represents a zero-profit condition (see equation (1)), applied to the aggregate energy subsector: in equilibrium, the value of produced energy goods and services equals the market value of resource rents and variable costs of energy production.

Beyond the direct integration of bottom-up activity analysis, the complementarity representation readily accomodates income effects and important second-best characteristics such as tax distortions or market failures (externalities). The latter are typically incoporated through explicit bounds on decisions variables such as prices or activity levels. Examples of price constraints may include lower bounds on the real wage or prescribed price caps (upper bounds) on energy goods. As to quantity constraints, examples may include administered bounds on the share of specific energy sources (e.g. renewables or nuclear power) or target levels for the provision of public goods. Associated with these constraints are complementary variables. In the case of price constraints, a rationing variable applies as soon as the price constraint becomes binding; in the case of quantity constraints, a complementary endogenous subsidy or tax is introduced.

\section{A Maquette}

As a pedagogic introduction to the ideas introduced in the previous section, we now provide a concrete example of the integration of bottom-up technological details into a top-down general equilibrium framework. We consider a stylized representation of the world economy with basic 
economic transactions displayed in Table $1 .{ }^{6}$

After describing a static setting without investment activities we subsequently lay out an intertemporal extension of the static model where agents make explicit choices at the margin between current and future consumption based on consistent expectations of future prices.

To maintain transparency and simplicity in this exposition, we formulate a model involving a single macroeconomic good and a representative consumer. Extensions of the model to deal with multiple non-energy goods and multiple households are, in our view, relatively straightforward.

\subsection{A Static Model}

We consider a model in with a single non-energy good produced under constant returns to scale using inputs of labor, capital, and energy. The economy is closed. Three fossil fuels (oil, coal and natural gas) are produced subject to decreasing returns to scale. Final consumption demand includes non-energy goods, electricity, and non-electric energy. To maintain clarity, we initially consider an economy in the absence of taxes or public goods provision.

Following the structure of the Arrow-Debreu model presented above, we denote decision variables in the model as follows:

- Activity levels:

$Y \quad$ is the production of non-energy good,

$X_{f}$ refers to the supply of fossil-fuel $f \in\{$ oil, coal, gas $\}$,

$E_{t}$ denotes the production of electricity by technology $t$,

$C$ refers to composite final consumption, and

$W \quad$ is the full consumption (utility) including leisure.

- Market prices:

$p_{Y} \quad$ is the price of non-energy output,

$p_{C} \quad$ is the price of the final consumption composite,

$p_{\text {ELE }}$ denotes the electricity price,

$p_{f} \quad$ denotes the price of fossil fuel $f$,

$p_{L} \quad$ refers to the price of labor,

$r_{K} \quad$ is the rental price of capital,

$p_{W} \quad$ is the utility price index,

$\mu_{t} \quad$ is the shadow price on generating capacity, and

$r_{f} \quad$ is the rental rate on fossil fuel resources ( $f \in\{$ oil, coal, gas $\left.\}\right)$.

- Income levels:

$M$ portrays income of the representative household.

\footnotetext{
${ }^{6}$ The numbers stem from the GTAP 6 database which reports consistent accounts of national production and consumption as well as bilateral trade and energy flows for the year 2001 (Dimaranan and Dougall (2006)).
} 
On the production side, firms minimize costs of producing output subject to nested constantelasticity-of-substitution (CES) functions that describe the price-dependent use of factors and intermediate inputs. In the production of non-energy output, fossil fuels trade off in the lowest nest with a constant elasticity of substitution. At the next level, the fossil fuel composite is combined with electricity at constant value shares (Cobb-Douglas). The energy aggregate and a Cobb-Douglas value-added composite enter the top level with a constant elasticity of substitution. The unit-profit function of macro-good production is:

$$
\Pi^{Y}=p_{Y}-\left\{\theta_{K L}\left(p_{L}^{\theta_{L}} r_{K}^{1-\theta_{L}}\right)^{1-\sigma_{Y}}+\left(1-\theta_{K L}\right) *\left(p_{E L E}^{\theta_{E L E}}\left(\sum_{f} \theta_{f}^{Y} p_{f}^{1-\sigma_{E}}\right)^{\frac{1-\theta_{E L E}}{1-\sigma_{E}}}\right)^{1-\sigma_{Y}}\right\}^{\frac{1}{1-\sigma_{Y}}}
$$

where:

$\theta_{K L} \quad$ is the cost share of the value-added composite in production,

$\theta_{L} \quad$ denotes the labor cost share within the value-added composite in production,

$\theta_{E L E}$ represents the electricity value share within the aggregate energy demand of production,

$\theta_{f}^{Y} \quad$ is the cost share of fossil fuel $f$ within the non-electric energy composite of production,

$\sigma_{Y} \quad$ is the elasticity of substitution between the value-added composite and aggregate energy in production,

$\sigma_{E} \quad$ is the elasticity of substitution between electricity and the non-electric energy composite in production, and

$Y \quad$ is the associated complementary variable.

Fossil fuels are produced with a fuel-specific resource and a non-resource composite trading off with a constant elasticity of substitution. The unit-profit function for fossil fuel production is:

$$
\Pi_{f}^{F}=p_{f}-\left\{\theta_{f}^{R} r_{f}^{1-\sigma_{f}}+\left(1-\theta_{f}^{R}\right)\left(\theta_{f}^{L} p_{L}+\theta_{f}^{K} r_{K}+\theta_{f}^{Y} p_{Y}+\theta_{f}^{E L E} p_{E L E}+\sum_{f f} \theta_{f f}^{f} p_{f f}\right)^{1-\sigma_{f}}\right\}^{\frac{1}{1-\sigma_{f}}}
$$

where: 
$\theta_{f}^{R} \quad$ denotes the cost share of resources,

$\theta_{f}^{L} \quad$ is the labor cost share in the non-resource composite input,

$\theta_{f}^{K} \quad$ refers to the capital cost share in the non-resource composite input,

$\theta_{f}^{Y} \quad$ is the macro-good cost share in the non-resource composite input,

$\theta_{f}^{E L E} \quad$ denotes the electricity cost share in the non-resource composite input,

$\theta_{f f}^{f} \quad$ refers to the cost share of fossil fuel $f f$ (aliased with $f$ ) in the non-resource composite input,

$\sigma_{f} \quad$ is the elasticity of substitution between the fossil fuel resource and the composite of non-resource inputs, and

$X_{f} \quad$ is the associated complementary variable.

In our stylized example, we illustrate the integration of bottom-up activity analysis into the top-down representation of the overall economy through our portrayals of the electricity sector. Rather than describing electricity generation by means of a CES production function, we capture production possibilities by Leontief technologies that are active or inactive in equilibrium depending on their profitability. The detailed technological representation can be necessary for an appropriate assessment of selected policies. For example, energy policies may prescribe target shares of specific technologies in overall electricity production such as green quotas or the gradual elimination of certain power generation technologies such as a nuclear phase-out. We can write the unit-profit functions of power generation technologies as:

$$
\Pi_{t}^{E}=p_{\mathrm{ELE}}-a_{t}^{Y} p-a_{t}^{K} r_{K}-a_{t}^{L} p_{L}-\sum_{f} a_{f t}^{F} p_{f}-\mu_{t}
$$

where:

$a_{t}^{Y} \quad$ denotes the macro-good input coefficient for technology $t$

$a_{t}^{K} \quad$ is the capital input coefficient,

$a_{t}^{L} \quad$ refers to the labor input coefficient,

$a_{f t}^{F} \quad$ is the energy input coefficient (e.g. coal, oil, or gas inputs), and

$E_{t} \quad$ is the associated complementary variable.

Final consumption demand is characterized by a composite good with a three-level nested CES technology. Fossil fuels enter in the third level (non-electric) energy nest at a unitary elasticity of substitution. The non-electric energy composite is combined at the second level with electricity subject to a constant elasticity of substitution. At the top level the energy aggregate trades off with non-energy macro-good demand at a constant elasticity of substitution. The unit-profit function 
for final consumption is written:

$$
\Pi^{C}=p_{C}-\left\{\theta_{C} p_{Y}^{1-\sigma_{C}}+\left(1-\theta_{C}\right)\left[\theta_{E L E}^{C} p_{\mathrm{ELE}}^{1-\sigma_{E L E}^{C}}+\left(1-\theta_{E L E}^{C}\right)\left(\prod_{f} p_{f}^{\theta_{f}^{C}}\right)^{1-\sigma_{E L E}^{C}}\right]^{\frac{1-\sigma_{C}}{1-\sigma_{E L E}^{C}}}\right\}^{\frac{1}{\left(1-\sigma_{C}\right)}}
$$

where:

$\theta_{C} \quad$ represents the non-energy share of expenditure,

$\theta_{E L E}^{C} \quad$ refers to the electricity value share of energy demand in final consumption,

$\theta_{f}^{C} \quad$ is the value share of fossil fuel $f$ within the non-electric energy demand of final consumption,

$\sigma_{C} \quad$ is the compensated elasticity of substitution between energy and non-energy in final demand,

$\sigma_{E L E}^{C} \quad$ is the compensated elasticity of substitution between electric and non-electric energy in final demand, and

$C \quad$ is the associated complementary variable.

Final consumption demand is combined with leisure at a constant elasticity of substitution to form an aggregate utility good. The unit-profit function for aggregate utility is written:

$$
\Pi^{W}=p_{W}-\left\{\theta_{W} p_{L}^{1-\sigma_{W}}+\left(1-\theta_{W}\right) p_{C}^{1-\sigma_{W}}\right\}^{\frac{1}{1-\sigma_{W}}}
$$

where:

$\theta_{W}$ represents the leisure value share of aggregate utility,

$\sigma_{W}$ is the compensated elasticity of substitution between leisure and the final consumption composite, and

$W \quad$ is the associated complementary variable.

In our stylized economy, a representative household is endowed with primary factors labor (more generally: time), capital, and resources for fossil fuel production. The representative household maximizes utility from consumption subject to available income. Total income of the household consists of factor payments and scarcity rents on capacity constraints:

$$
M=p_{L} \bar{Z}+r_{K} \bar{K}+\sum_{f} r_{f} \bar{R}_{t}+\sum_{t} \mu_{t} \bar{E}_{t}
$$

where:

$\bar{Z}$ denotes the aggregate endowment with time,

$\bar{K}$ represents the aggregate capital endowment,

$\bar{R}_{f} \quad$ refers to the resource endowment with fossil fuel $f$, and

$\bar{E}_{t}$ denotes the generation capacity for technology $t$. 
Flexible prices on competitive markets for factors and goods assure balance of supply and demand. Using Hotelling's lemma, we can derive compensated supply and demand functions of goods and factors.

Market clearance conditions for our stylized economy then read as:

- Labor market clearance:

$$
\bar{Z}-\frac{\partial \Pi^{W}}{\partial p_{L}} W \geq \frac{\partial \Pi^{Y}}{\partial p_{L}} Y+\sum_{f} \frac{\partial \Pi^{F}}{\partial p_{L}} x_{f}+\sum_{t} a_{t}^{L} E_{t}
$$

where $p_{L}$ is the associated complementary variable.

- Capital market clearance:

$$
\bar{K} \geq \frac{\partial \Pi^{Y}}{\partial r_{K}} Y+\sum_{f} \frac{\partial \Pi^{F}}{\partial r_{K}} x_{f}+\sum_{t} a_{t}^{K} E_{t}
$$

where $r_{K}$ is the associated complementary variable.

- Market clearance for fossil fuel resources:

$$
\bar{R}_{f} \geq \frac{\partial \Pi_{f}^{F}}{\partial r_{f}} X_{f}
$$

where $r_{f}$ is the associated complementary variable.

- Market clearance for electricity generation capacities:

$$
\bar{E}_{t} \geq E_{t}
$$

where $\mu_{t}$ is the associated complementary variable.

- Market clearance for the non-energy macro good:

$$
Y \geq \sum_{f} \frac{\partial \Pi^{F}}{\partial p_{Y}} x_{f}+\sum_{t} a_{t}^{Y} E_{t}+\frac{\partial \Pi^{C}}{\partial p_{Y}} C
$$

where $p_{Y}$ is the associated complementary variable.

- Market clearance for fossil fuels

$$
X_{f} \geq \frac{\partial \Pi^{Y}}{\partial p_{f}} Y+\sum_{f f \neq f} \frac{\partial \Pi^{F}}{\partial p_{f} f} x_{f f}+\sum_{t} a_{f t}^{F} E_{t}+\frac{\partial \Pi^{C}}{\partial p_{f}} C
$$

where $p_{f}$ is the associated complementary variable. 
- Market clearance for electricity:

$$
\sum_{t} X_{t} \geq \frac{\partial \Pi^{Y}}{\partial p_{E L E}} Y+\sum_{f} \frac{\partial \Pi^{F}}{\partial p_{E L E}} x_{f}+\frac{\partial \Pi^{C}}{\partial p_{E L E}} C
$$

where $p_{E L E}$ is the associated complementary variable.

- Market clearance for the final consumption composite:

$$
C \geq \frac{\partial \Pi^{W}}{\partial p_{C}}
$$

where $p_{C}$ is the associated complementary variable.

- Market clearance for the aggregate utility good:

$$
W \geq \frac{M}{p_{W}}
$$

where $p_{W}$ is the associated complementary variable.

As to the parameterization of our simple numerical model, benchmark prices and quantities, together with exogenous elasticities determine the free parameters of the functional forms that describe technologies and preferences.

Table 1 describes the benchmark equilibrium in terms of a social accounting matrix (King (1985)). In a microconsistent social accounting matrix data, consistency requires that the sums of entries across each of the rows and columns equal zero: Market equilibrium conditions are associated with the rows, the columns capture the zero-profit condition for production sectors as well as the income balance for the aggregate household sector. Benchmark data are typically reported as values, i.e. they are products of prices and quantities. In order to obtain separate price and quantity observations, the common procedure is to choose units for goods and factors so that they have a price of unity (net of potential taxes or subsidies) in the benchmark equilibrium. Then, the value terms simply correspond to the physical quantities. ${ }^{7}$ Table 2 provides a summary of elasticities of substitution underlying our central case simulations. Table 3 lists the initial endowments of the economy with time, capital, and fossil fuel resources. Table 4 provides a bottom-up description of initially active power technologies (here: gas-fired power plants, coal-fired power plants, nuclear power plants, and hydro power plants) for the base year. Note that the benchmark outputs of active technologies sum up to economy-wide electricity demand while input requirements add up to aggregate demands as reported in the social accounting matrix. In our exposition, we impose consistency of aggregate top-down data with bottom-up technology data. In modelling practise, the harmonization of bottom-up data with top-down data may require substantial data adjustments

\footnotetext{
${ }^{7}$ Of course, one could adopt relative prices different from one and rescale physical quantities accordingly without affecting the equilibrium properties.
} 
to create a consistent database for the hybrid model. Table 5 includes bottom-up technology coefficients (cost data) for initially inactive technologies (here: wind, solar, and biomass). In our central case simulations, unit-output of inactive wind, biomass, and solar technologies are characterized by a technology-specific cost disadvantage vis--vis the electricity price in the base year: wind is listed as $10 \%$ more costly, biomass as $30 \%$ and solar as $100 \%$. We furthermore assume hydro power and nuclear power plants to operate at upper capacity levels (initially with zero shadow prices) due to natural resource and exogenous policy constraints.

\subsection{A Dynamic Extension of the Model}

Policy interference can substantially affect investment and savings incentives. Assessment of the adjustment path and long-term equilibrium effects induced by policy constraints may therefore call for an explicit intertemporal framework.

Dynamic modeling requires an assumption on the degree of foresight of economic agents. In a deterministic setting, one logically consistent approach is to assume that agents in the model know as much about the future as the modeler: Agents' expectations of future prices then correspond to realized future prices in the simulation. Within the standard Ramsey model of savings and investment, the notion of perfect foresight is coupled with the assumption of an infinitely-lived representative agent who makes explicit choices at the margin between the consumption levels of current and future generations. The representative agent maximizes welfare subject to an intertemporal budget constraint. Savings rates equalize the marginal return on investment and the marginal cost of capital formation. Rates of return are determined such that the marginal productivity of a unit of investment and marginal utility of foregone consumption are equalized.

Casting our static model into an intertemporal version only requires a few modifications, since most of the underlying economic relationships are strictly intra-period and, therefore, hold on a period-by-period basis in the dynamic extension. Regarding capital stock formation and investment, an efficient allocation of capital, i.e. investment over time, implies two central intertemporal zeroprofit conditions which relate the cost of a unit of investment, the return to capital, and the purchase price of a unit of capital stock in period $\tau$.

Firstly, in equilibrium, the market value of a unit of depreciated capital purchased at the beginning of period $t$ can be no less than the value of capital rental services through that period and the value of the unit of capital sold at the start of the subsequent period (zero-profit condition of capital formation):

$$
-\Pi_{\tau}^{K}=p_{\tau}^{K}-r_{\tau}^{K}-(1-\delta) p_{\tau+1}^{K} \geq 0
$$

Secondly, the opportunity to undertake investments in year $\tau$ limits the market price of capital in period $\tau+1$ (zero-profit condition of investment):

$$
-\Pi_{\tau}^{I}=-p_{\tau+1}^{K}+p_{\tau}^{Y} \geq 0
$$


Furthermore, capital evolves through geometric investment and geometric depreciation:

$$
K_{i, \tau+1}=(1-\delta) K_{i, \tau}+I_{i, \tau}
$$

Finally, output markets in the dynamic model must account for intermediate demand, final consumption demand and investment demand:

$$
Y \geq \sum_{f} \frac{\partial \Pi^{F}}{\partial p_{Y}} x_{f}+\sum_{t} a_{t}^{Y} E_{t}+\frac{\partial \Pi^{C}}{\partial p_{Y}} C+I_{\tau}
$$

The foregoing equations have introduced $\delta$, the capital depreciation rate, and three additional variables: $p_{\tau}^{K}$ is the value (purchase price) of one unit of capital stock in period $\tau$,

$K_{\tau}$ is the associated dual variable which indicates the activity level of capital stock formation in period $\tau$, and

$I_{\tau} \quad$ is the associated dual variable which indicates the activity level of aggregate investment in period $\tau$.

In our intertemporal model demand responses arise from behavioral choices consistent with maximization of a infinitely-lived representative agent. This consumer allocates lifetime income, i.e., the intertemporal budget, over time in order to maximize utility, solving:

$$
\max \sum_{\tau}\left(\frac{1}{1+\rho}\right)^{\tau} u\left(C_{\tau}\right)
$$

subject to

$$
\sum_{\tau} p_{\tau}^{C} C_{\tau}=M
$$

where:

$u($.$) denotes the instantaneous utility function of the representative agent, and$

$\rho \quad$ is the time preference rate, and

$M \quad$ represents lifetime income (from endowments with capital, time, and resources).

With isoelastic lifetime utility the instantaneous utility function is given as:

$$
u(c)=\frac{c^{1-\frac{1}{\eta}}}{1-\frac{1}{\eta}}
$$

where $\eta$ is a constant intertemporal elasticity of substitution.

The finite model horizon poses some problems with respect to capital accumulation. Without any terminal constraint, the capital stock at the end of the model's horizon would have no value and this would have significant repercussions for investment rates in the periods leading up to the end of the model horizon. In order to correct for this effect, we define a terminal constraint 
which forces investment to increase in proportion to final consumption demand. Since the model is formulated as a mixed complementarity problem one can include the post-terminal capital stock as an endogenous variable. Using state variable targeting for this variable, the growth of investment in the terminal period can be related to the growth rate of capital or any other "stable" quantity variable in the model (Lau, Pahlke and Rutherford (2002)).

For the calibration of the dynamic model we adopt central case values of $5 \%$ for the time preference rate (i.e. the baseline interest rate), $2 \%$ for the growth rate of labor in efficiency units, and $7 \%$ for the depreciation rate of capital. These parameter values then are used to infer the value of payments to capital across sectors and the gross value of capital formation in consistency with a balanced steady-state growth path. The value for the constant intertemporal elasticity of substitution $\eta$ is set at 0.5 .

\section{Policy Simulations}

In this section, we illustrate the use of our stylized hybrid bottom-up/top-down model for the economic assessment of three initiatives that figure prominently on the energy policy agenda of many industrialized countries: (i) nuclear phase-out, (ii) target quotas for renewables in electricity production (green quotas), and (iii) environmental tax reforms.

For each policy initiative, we first report impacts for the static model and then present the effects for the dynamic model. ${ }^{8}$ The dynamic model covers a time horizon of roughly a 100 years (starting in 2005 and ending in 2100) at annual steps. In accordance with the static model setting, we first compute an off-the-steady-state baseline accounting for resource limits on renewables (here: hydro power is limited to the base-year level) and policy constraints on nuclear power (nuclearcan not exceed the base-year level). The implications of policy interference are measured against the respective baseline path (the business-as-usual $B a U$ ) and reported in decadal periods.

An important caveat applies: Reflecting our primary pedagogic objective, both the policy scenarios as well as the model formulations are highly stylized such that we caution against too literal an interpretation of the numerical results.

\subsection{Nuclear Phase-Out}

Reservations against the use of nuclear power are reflected in policy initiatives of several EU Member States (e.g. Belgium, Germany, the Netherlands, Spain, and Sweden) that foresee a gradual phaseout of their nuclear power programs (IEA (2001)). In our hybrid model, policy constraints on the use of nuclear power can be easily implemented via parametric changes of upper bounds on the permissible generation capacity.

\footnotetext{
${ }^{8}$ Our results section is restrained to the central case parameterization. The interested reader can alter the parameterization in the computer programs of the download to perform sensitivity analysis.
} 
Figure 1 reports static welfare changes - measured in terms of Hicksian equivalent variation in income - as a function of upper bounds to nuclear power generation. Welfare impacts are depicted for two alternative assumptions regarding technological backup options. The case labeled as "Fossil" does not restrict the use of fossil power technologies whereas the case labeled as "No fossil" restricts fossil-fuel based power generation to the initial (base-year) level. Obviously, the welfare cost of a nuclear phase-out are much higher as we impose additional restrictions on the phase-in of competitive power generation based on fossil fuels (for example due to climate policy considerations). In the case "Fossil", nuclear power is backed up by an increase in fossil power generation whereas renewable technologies - apart from hydro which is already operated at the upper bound in the reference situation - remain slack activities. If we forbid expansion of fossil power generation, wind power takes up the role of the primary nuclear backup given our illustrative cost parameterization of technologies. For the later case (i.e. "No Fossil"), Figure 2 illustrates the changes in the supply of electricity across technologies as a function of upper bounds to nuclear power generation.

In the dynamic model setting, we investigate a linear phase-out of nuclear power between 2010 and 2030. Figure 3 depicts the implications for investment, consumption, and aggregate electricity supply through time. During the phase-out period, investment and electricity supply are distinctly supressed, recovering to some extent in the long run, however at levels below the baseline. Aggregate consumption over time is markedly lower than in the baseline which reflects the loss in lifetime income due to the policy-driven technology constraints.

\subsection{Green Quotas}

Renewable energy technologies have received political support within the EU since the early 1970's. After the oil crises, renewable energy was primarily seen as a long-term substitution to fossil fuels in order to increase EU-wide security of supply. In the context of anthropogenic climate change, the motive has shifted to environmental concerns: Renewables are considered as an important alternative to thermal electricity in order to reduce carbon emissions from fossil fuel combustion. In 2001, the EU Commission issued a Directive which aims at doubling the share of renewable energy in EU-wide gross energy consumption in 2010 as compared to 1997 levels (European Commission (EC) (2001)). In our stylized framework, we can implement the imposition of green quotas by setting a cumulative quantity constraint on the share of electricity that comes from renewable energy sources. This quantity constraint is associated with a complementary endogenous subsidy on renewable electricity production which - in our case - is paid by the representative household. The associated modifications of our basic algebraic model include (i) an explicit quantity constraint for the target quota, (ii) an endogenous subsidy on green electricity production as the associated complementary decision variable, and (iii) the adjustment of the income constraint to account for overall subsidy payments. In the base-year the share of electricity produced by renewable energy sources (here: 
hydro power) amounts to roughly $18 \%$. In our static policy counterfactuals, we subsequently increase this share by 10 percentage points up to a quota of $28 \%$. We perform sensitivity analysis regarding capital malleability embodied in extant technologies: Reflecting a static short-run analysis - labeled as "Short run" - we assume that capital embodied in extant technologies is not malleable, whereas the static long-run analysis - labeled as "Long run" - presumes fully malleable (mobile) capital across all sectors and technologies.

Figures 4 and 5 report differences between the static short- and long-run implications for economic welfare and subsidy rates. As expected, the economic cost of pushing green power production is more pronounced if we restrict capital malleability of extant technologies ("sunk cost"). Likewise, subsidy rates in the short-run must be substantially higher to make renewables break even.

In the dynamic analysis of green quotas, we impose a linear increase between 2010 and 2030 by $10 \%$ over the base-year share of $18 \%$. Figure 6 visualizes the policy-induced changes of investment, consumption, and aggregate electricity supply over time. Lump-sum subsidies to renewable power technologies lead to an increase in overall investment together with a rise in electricity supply. Consumption drops below baseline levels over the full time horizon indicating the welfare cost of the transition towards a "greener" power system.

\subsection{Environmental Tax Reform}

Over the last decade, several EU Member States have levied some type of carbon tax in order to reduce greenhouse gas emissions from fossil fuel combustion that contribute to anthropogenic global warming(OECD (2001)). In this context, the debate on the double dividend hypothesis has addressed the question of whether the usual trade-off between environmental benefits and gross economic costs (i.e. the costs disregarding environmental benefits) of emission taxes prevails in economies where distortionary taxes finance public spending. Emission taxes raise public revenues which can be used to reduce existing tax distortions. Revenue recycling may then provide prospects for a double dividend from emission taxation (Goulder (1995)): Apart from an improvement in environmental quality (the first dividend), the overall excess burden of the tax system may be reduced by using additional tax revenues for a revenue-neutral cut of existing distortionary taxes (the second dividend). If - at the margin - the excess burden of the environmental tax is smaller than that of the replaced (decreased) existing tax, public financing becomes more efficient and welfare gains will occur.

Since our hybrid model - formulated as a mixed complementarity problem - is not limited by integrability constraints, we can use it to investigate the scope for a double dividend. In a first step, we refine Table 1 which reports base year economic flows on a gross of tax basis in order to reflect initial taxes and public consumption. For the sake of simplicity, we assume that public demand amounts to some fixed share of base year non-energy final consumption (in our case: 15\%). Public consumption is financed by distortionary taxes on labor supply (with an initial input tax rate of 
$50 \%$ ) and the final consumption of the non-energy macro good (with an initial consumption tax rate of $17.6 \%)$.

In our static policy simulations, we investigate the economic effects of carbon taxes that are set sufficiently high to reduce carbon emissions by $5 \%, 10 \%, 15 \%$, and $20 \%$ compared to the base year emission level. While keeping public good consumption at the base-year level, the additional carbon tax revenues can be recycled in three different ways: (i) a lump-sum refund to the representative household (labeled as "LS"), (ii) a cut in the distortionary consumption tax (labeled as "TC"), and (iii) a reduction in the distortionary labor tax (labeled as "TL").

Figure 7 depicts the welfare implications of the described environmental tax reforms in our static model. The first insight - in line with the undisputed weak double dividend hypothesis (see Goulder 1995) - is that the reduction of the distortionary consumption or labor taxes is superior in efficiency terms as compared to a lump-sum recycling of carbon tax revenues. For our stylized parameterization, we even obtain a strong double dividend from revenue-neutral cuts in distortonary taxes: Reflecting the larger marginal excess burden of the initial labor tax vis--vis the initial consumption tax, labor tax recycling is distinctly more beneficial than consumption tax recycling. Figure 8 reports the associated carbon tax rates to achieve the target emission reductions. Tax rates - as the direct incentive for emission mitigation in production and consumption - increase with the stringency of the emission constraint but hardly differ across recycling variants.

In the dynamic analysis of environmental tax reforms, we impose a linear reduction of carbon emissions compared to baseline emission levels by $20 \%$ between 2010 and 2030, holding the percentage reduction vis--vis the $B a U$ constant thereafter. Figure 7 provides the consumption trajectories for the three different recycling variants. Like in the static simulations, the existence of a weak double dividend is evident. However, we may no longer obtain a strong double-dividend from revenue-neutral cuts of distortionary taxes: As we translate changes in consumption into Hicksian equivalent variation of lifetime income, welfare changes amount to $-0.22 \%$ for variant "LS", $-0.036 \%$ for variant "TC", and "0.068" for variant "TL". Hence, only for the case of labor tax recycling, is there the existence of a strong double dividend in our stylized scenario. In the case of consumption tax recycling, the negative tax-interaction effect of carbon taxes is not offset by the positive revenue-recycling effect of consumption tax rebates.

\section{Conclusions}

There is a commonly perceived dichotomy between top-down general equilibrium models and bottom-up energy system models dealing with energy issues. Bottom-up models provide a detailed description of the energy system from primary energy sources via multiple processes of conversion, transport, and distribution to final energy use, but these models neglect potentially important interactions of the energy sector and the rest of the economy. Furthermore, the formulation of 
such models as mathematical programs restricts their direct applicability to integrable equilibrium problems. Many interesting policy problems involving inefficiencies due to market distortions or market failures can therefore not be handled - except by resorting to iterative optimization methods (Rutherford (1999b)). Top-down general equilbrium models, on the other hand, are able to capture market interactions and inefficiencies in a comprehensive manner but typically lack technological details that might be relevant for the policy issue at hand.

In this paper, we have motivated the formulation of market equilibrium as a mixed complementarity problem to bridge the gap between bottom-up and top-down analysis. Through the explicit representation of weak inequalities and complementarity between decision variables and equilibrium conditions, the complementarity approach allows an analyst to exploit the advantages of each model type - technological details of bottom-up models and economic richness of top-down models - in a single mathematical format.

Despite the coherence of the integrated complementarity approach, dimensionality may impose limitations on its practical application. Bottom-up programming models of the energy system often involve a large number of bounds on decision variables. These bounds are treated implicitly in mathematical programs but introduce unavoidable complexity in the integrated complementarity formulation since they must be associated with explicit price variables in order to account for income effects. Therefore, future research may be dedicated to decomposition approaches that permit consistent combination of complex top-down models and large-scale bottom-up energy system models for energy policy analysis. 


\section{References}

Bahn, O., S. Kypreos, B. Büeler, and H. J. Luethi, "Modelling an international market of $\mathrm{CO}_{2}$ emission permits," International Journal of Global Energy Issues, 1999, 12, 283-291.

Böhringer, C., "The Synthesis of Bottom-Up and Top-Down in Energy Policy Modeling," Energy Economics, 1998, 20 (3), 233-248.

Bosetti, V., C. Carraro, M. Galeotti, E. Massetti, and M. Tavoni, "WITCH: A World Induced Technical Change Hybrid Model," Energy Journal - Special Issue, 2006, pp. 13-38.

Brooke, A., D. Kendrick, and A. Meeraus, GAMS: A Users Guide, GAMS Development Corp., 1996.

Dimaranan, B. V. and R.A. Dougall, "Global trade, assistance, and production: The GTAP 6 Data Base," Technical Report, Center for Global Trade Analysis, Purdue University 2006.

Dirkse, S. and M. Ferris, "The PATH Solver: A Non-monotone Stabilization Scheme for Mixed Complementarity Problems," Optimization Methods 83 Software, 1995, 5, 123-156.

Drouet, L., A. Haurie, M. Labriet, P. Thalmann, M. Vielle, and L. Viguier, "A Coupled Bottom-up / Top-Down Model for GHG Abatement Scenarios in the Swiss Housing Sector," in R. Loulou, J. P. Waaub, and G. Zaccour, eds., Energy and Environment, Cambridge, 2005, pp. 27-62.

European Commission (EC), Directive 2001/77/EC on the Promotion of Electricity produced from Renewable Energy Sources (RES-E) in the internal electricity market 2001.

Goulder, L. H., "Environmental taxation and the double dividend: A readers guide," International Tax and Public Finance, 1995, 2, 157-183.

Hofman, K. and D. Jorgenson, "Economic and technological models for evaluation of energy policy," The Bell Journal of Economics, 1976, pp. 444-446.

Hogan, W. W. and J. P. Weyant, "Combined Energy Models," in J. R. Moroney, ed., Advances in the Economics of Energy and Ressources, 1982, pp. 117-150.

Hourcade, J.-C., M. Jaccard, C. Bataille, and F. Gershi, "Hybrid Modeling: New Answers to Old Challenges," Energy Journal-Special Issue, 2006, pp. 1-12.

Hurwicz, L., "What is the Coase Theorem?," Japan and the World Economy, 1999, 7, 49-75.

IEA, Nuclear Power in the OECD $2001 . \quad$ Available at: http://www.iea.org/textbase/nppdf/free/2000/nuclear2001.pdf.

King, B., "What is a SAM?," in "Social Accounting Matrices: A Basis for Planning," Washington D. C.: The World Bank, 1985.

Lau, M., A. Pahlke, and T. F. Rutherford, "Approximating Infinite-horizon Models in a Complementarity Format: A Primer in Dynamic General Eqilibrium Analysis," Journal of Economic Dynamics and Control, 2002, 26, 577-609. 
Manne, A. S., "ETA-MACRO: A Model of Energy Economy Interactions," Technical Report, Electric Power Research Institute, Palo Alto, California 1977.

Manne, A.S., R. Mendelsohn, and R.G. Richels, "MERGE: A Model for Evaluating Regional and Global Effects of GHG Reduction Policies," Energy Policy, 2006, 23, 17-34.

Mathiesen, L., "Computation of Economic Equilibrium by a Sequence of Linear Complementarity Problems," in A. Manne, ed., Economic Equilibrium - Model Formulation and Solution, Vol. 23 1985, pp. 144-162.

Messner, S. and L. Schrattenholzer, "MESSAGE-MACRO: Linking an Energy Supply Model with a Macroeconomic Module and Solving Iteratively," Energy - The International Journal, 2000, 25 (3), 267-282.

_ and M. Strubegger, "Ein Modellsystem zur Analyse der Wechselwirkungen zwischen Energiesektor und Gesamtwirtschaft," Öffentlicher Sektor - Forschungsmemoranden, 1987, 13, 1-24.

OECD, Database on environmentally related taxes in OECD countries 2001. Available at: http://www.oecd.org/env/policies/taxes/index.htm.

Pressman, I., "A Mathematical Formulation of the Peak-Load Problem," The Bell Journal of Economics and Management Science, 1970, 1, 304-326.

Russell, T., "Aggregation, Heterogeneity, and the Coase Invariance Theorem," Japan and the World Economy, 1999, 7, 105-111.

Rutherford, T. F., "Extensions of GAMS for Complementarity Problems Arising in Applied Economics," Journal of Economic Dynamics and Control, 1995, 19, 1299-1324.

, "Applied General Equilibrium Modelling with MPSGE as a GAMS Subsystem: An Overview of the Modelling Framework and Syntax," Computational Economics, 1999, 14, 1-46.

_ _ "Sequential Joint Maximization," in J.Weyant, ed., Energy and Environmental Policy Modeling, Vol. 18, Kluwer, 1999, chapter 9.

Schäfer, A. and H.D. Jacoby, "Experiments with a Hybrid CGE-Markal Model," Energy Journal - Special Issue, 2006, pp. 171-178.

Schumacher, K. and R.D. Sands, "Where are the Industrial Technologies in Energy-Economy Models? - An Innovative CGE Approach for Steel Production in Germany," Discussion Paper No. 605, DIW, Berlin 2006.

Takayma, T. and G. G. Judge, Spatial and Temporal Price and Allocation Models, Amsterdam: North-Holland, 1971. 
Table 1: Illustrative Base Year Equilibrium Data Set (bn. \$)

\begin{tabular}{|l|rrrrrr|}
\hline & $Y$ & $C O A$ & $G A S$ & $O I L$ & $E L E$ & $R A$ \\
\hline$Y$ & 30864 & -36 & -71 & -216 & -267 & -30274 \\
$C O A$ & -12 & 105 & & -15 & -78 & \\
$G A S$ & -83 & & 249 & -33 & -15 & -47 \\
$O I L$ & -721 & & -2 & 1151 & -61 & -367 \\
$E L E$ & -746 & -6 & -4 & -23 & 1126 & -347 \\
Labor & -17088 & -20 & -35 & -141 & -180 & 17464 \\
Capital & -12214 & -17 & -99 & -434 & -454 & 13218 \\
Rent & & -26 & -38 & -289 & & 353 \\
\hline
\end{tabular}

Key: ROI: rest of industry, COA: coal, GAS: gas

OIL: oil, ELE: electricity, RA: household

Table 2: Elasticities of Substitution in Production and Final Demand

\begin{tabular}{|l|r|}
\hline Value-added composite versus other inputs in macro-good production & $\sigma_{Y}=0.5$ \\
Fossil fuels in macro-good production & $\sigma_{E}=2$ \\
Resource versus other inputs in fossil fuel production & $\sigma_{\text {Coal }}=0.5$ \\
& $\sigma_{\text {Oil }}=0.25$ \\
& $\sigma_{G a s}=0.25$ \\
Energy versus non-energy inputs in final consumption & $\sigma_{C}=0.75$ \\
Electricity versus non-electric energy in final consumption & $\sigma_{E L E}^{C}=0.3$
\end{tabular}

Table 3: Endowments (in bn. at $\$$ unit prices)

\begin{tabular}{|l|c|}
\hline Time endowment & $\bar{Z}=30562$ \\
Capital endowment & $\bar{K}=13218$ \\
Resource endowments in fossil fuels & $\bar{R}_{\text {Coal }}=26$ \\
& $\bar{R}_{\text {Oil }}=38$ \\
& $\bar{R}_{\text {Gas }}=289$ \\
\hline
\end{tabular}


Table 4: Cost Structure of Technologies Active in the Base Year

\begin{tabular}{|l|rrrrr|}
\hline & coal & gas & oil & nuclear & hydro \\
\hline$E L E$ & 437 & 215 & 83 & 186 & 205 \\
$Y$ & -106 & -38 & -7 & -55 & -61 \\
$C O A$ & -78 & & & & \\
$G A S$ & & -86 & & & \\
$O I L$ & & & -61 & & \\
Labor & -72 & -26 & -4 & -37 & -41 \\
Capital & -181 & -65 & -11 & -94 & -103 \\
\hline
\end{tabular}

Table 5: Cost Structure of Technologies Inactive in the Base Year

\begin{tabular}{|l|rrr|}
\hline & wind & biomass & solar \\
\hline$E L E$ & 1 & 1 & 1 \\
$Y$ & -0.1 & -0.5 & -0.1 \\
Capital & -0.9 & -0.5 & -1.8 \\
Labor & -0.1 & -0.3 & -0.1 \\
Wind & -1 & & \\
Trees & & -1 & \\
Sun & & & -1 \\
\hline
\end{tabular}




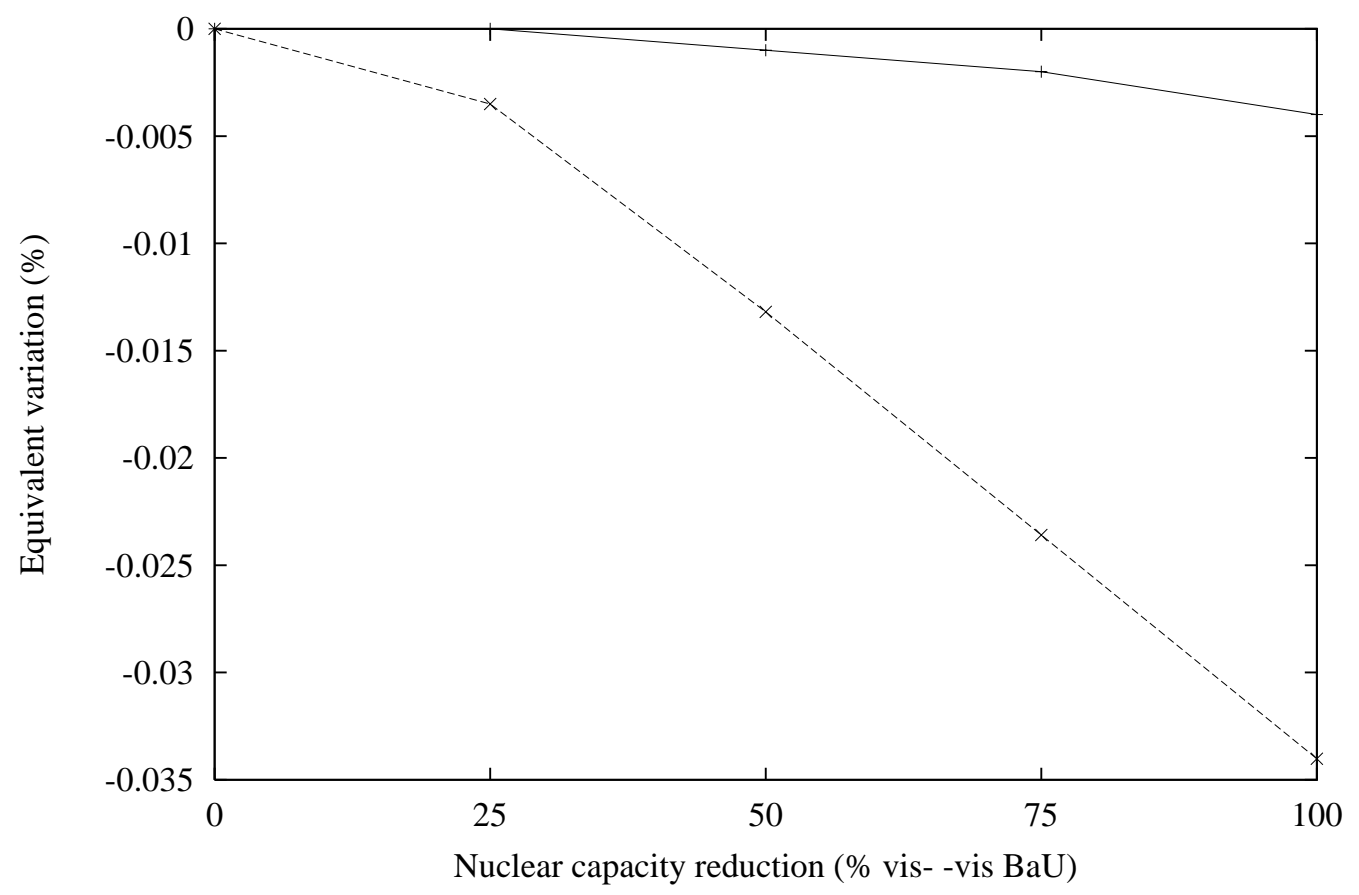

Fossil —_ No fossil ----*---

Figure 1: Static Welfare Effects of Nuclear Phase-Out 


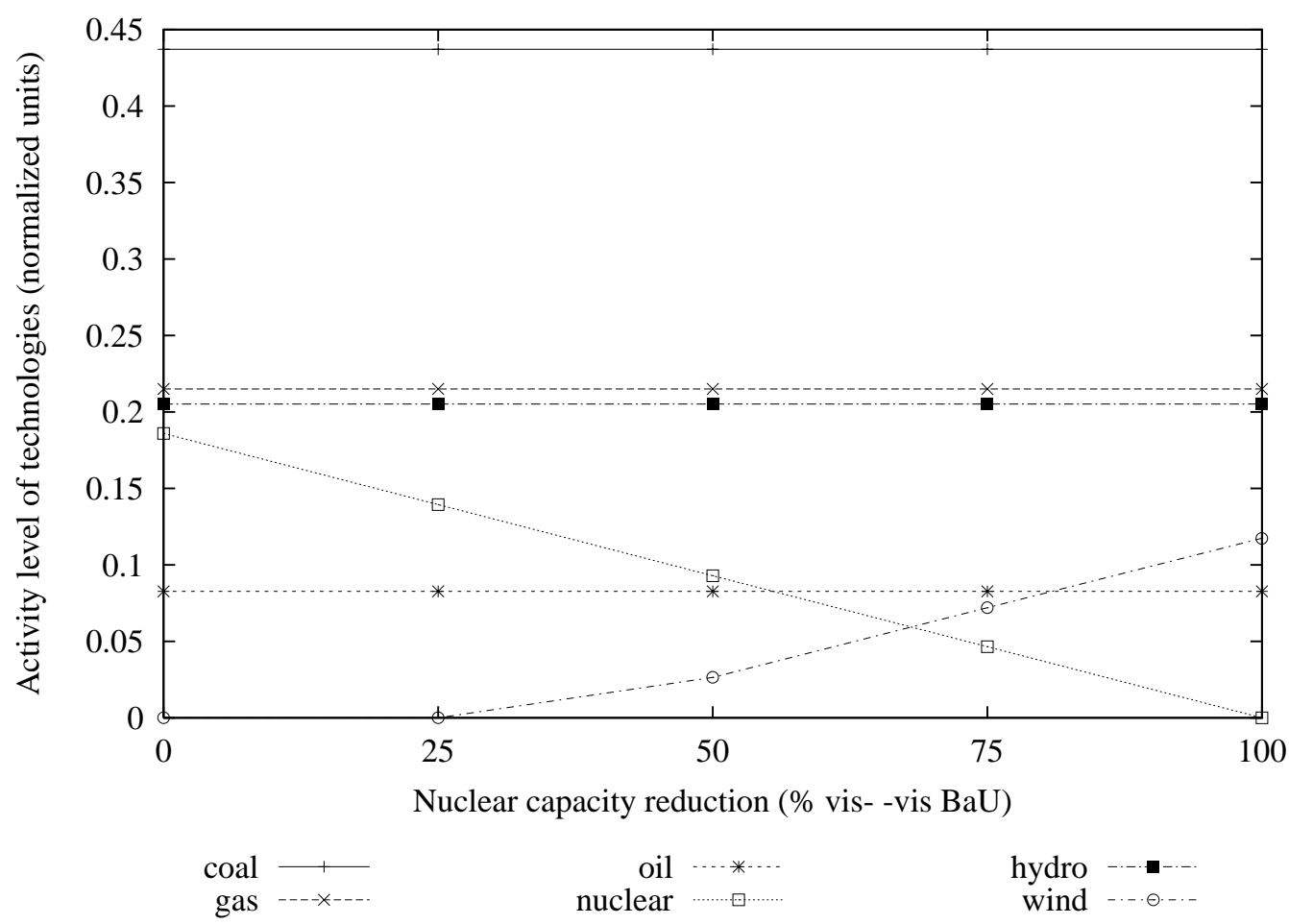

Figure 2: Static Technology Shifts in Power Production for Nuclear Phase-Out 


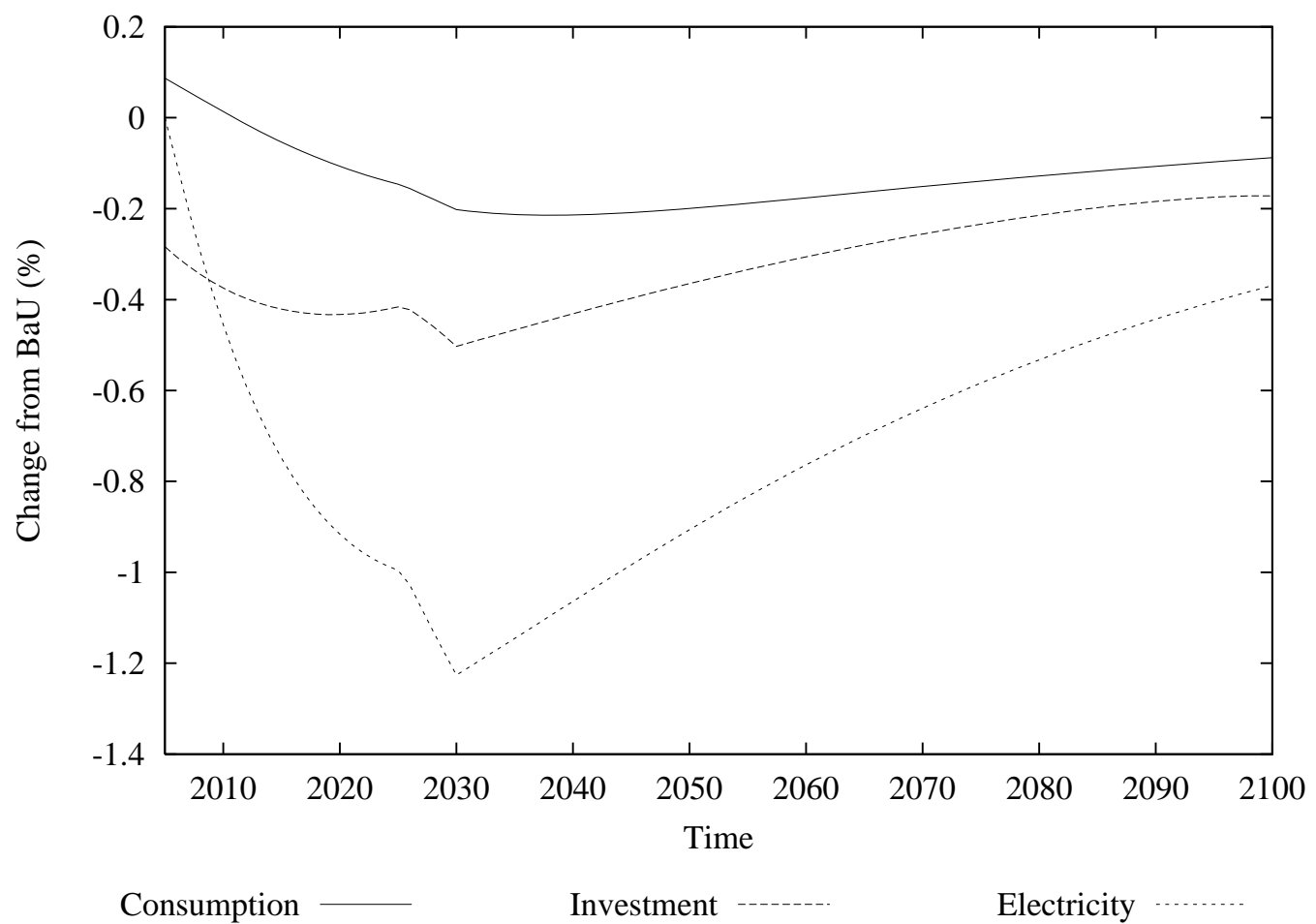

Figure 3: Dynamic Impacts of Nuclear Phase-Out (Variant: "No Fossil") 


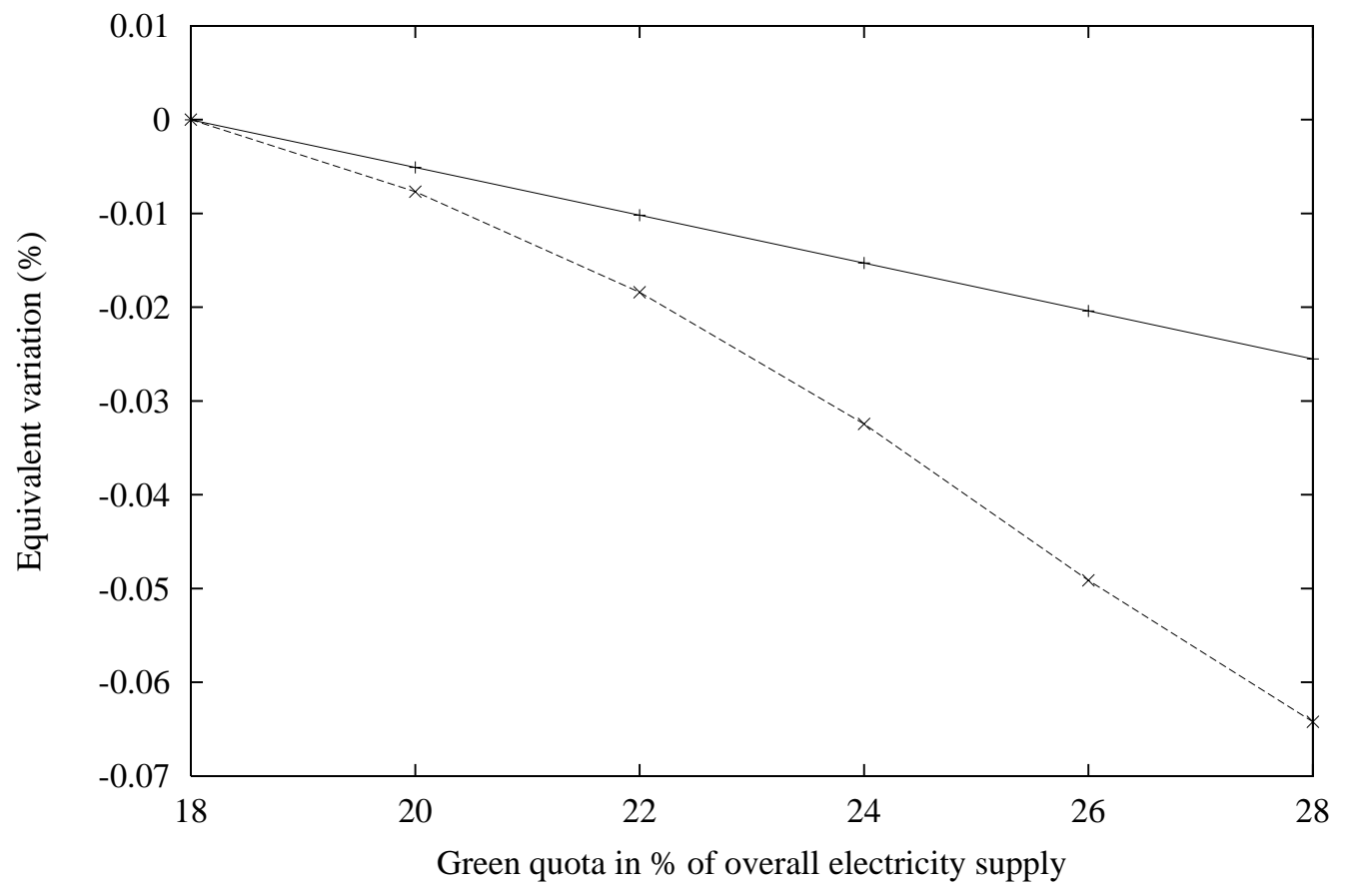

Long run $\longrightarrow$

Short run $----x--$

Figure 4: Static Welfare Effects of Green Quotas 


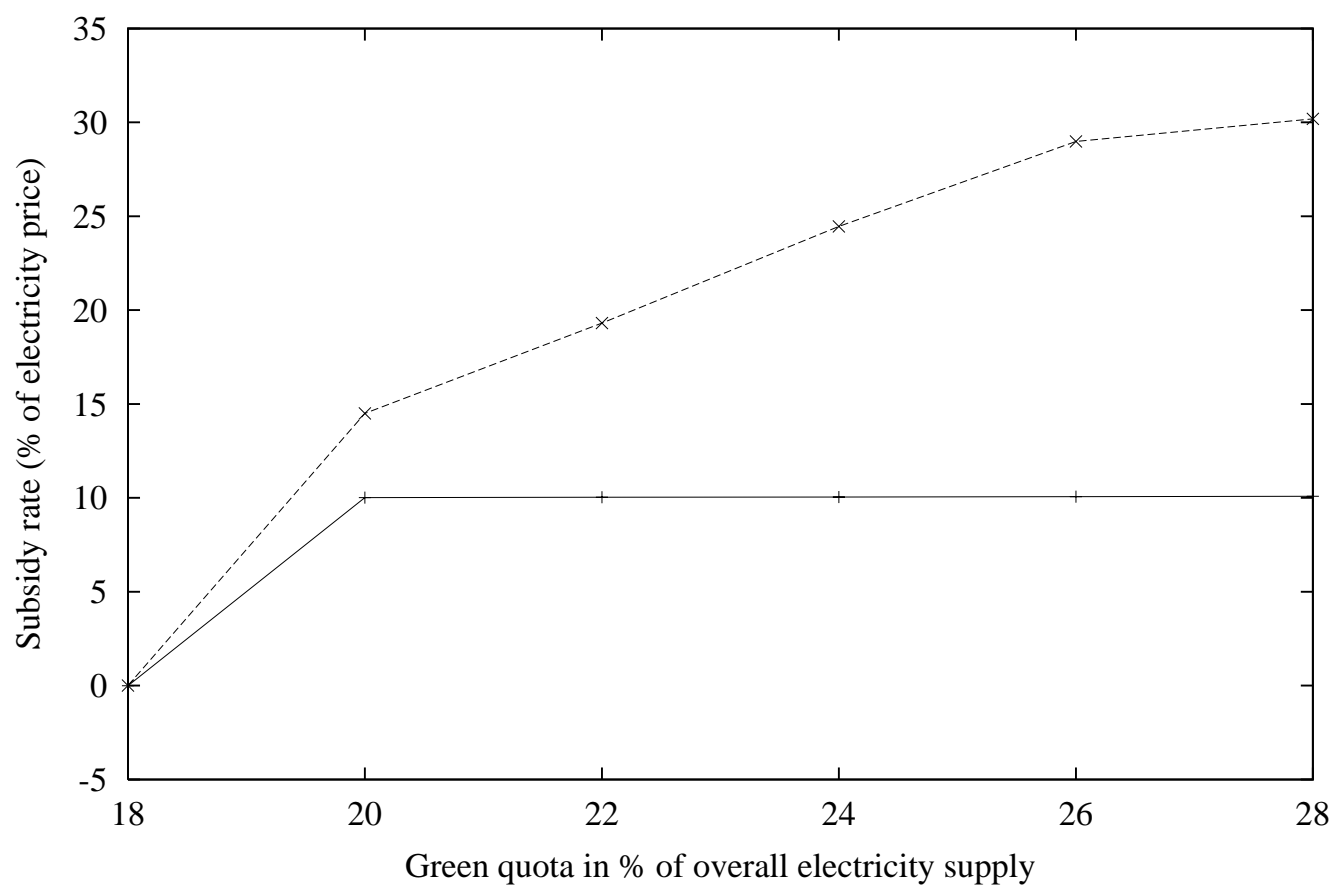

Long run $-1-\quad$ Short run ---*---.

Figure 5: Static Subsidy Rates of Green Quotas 


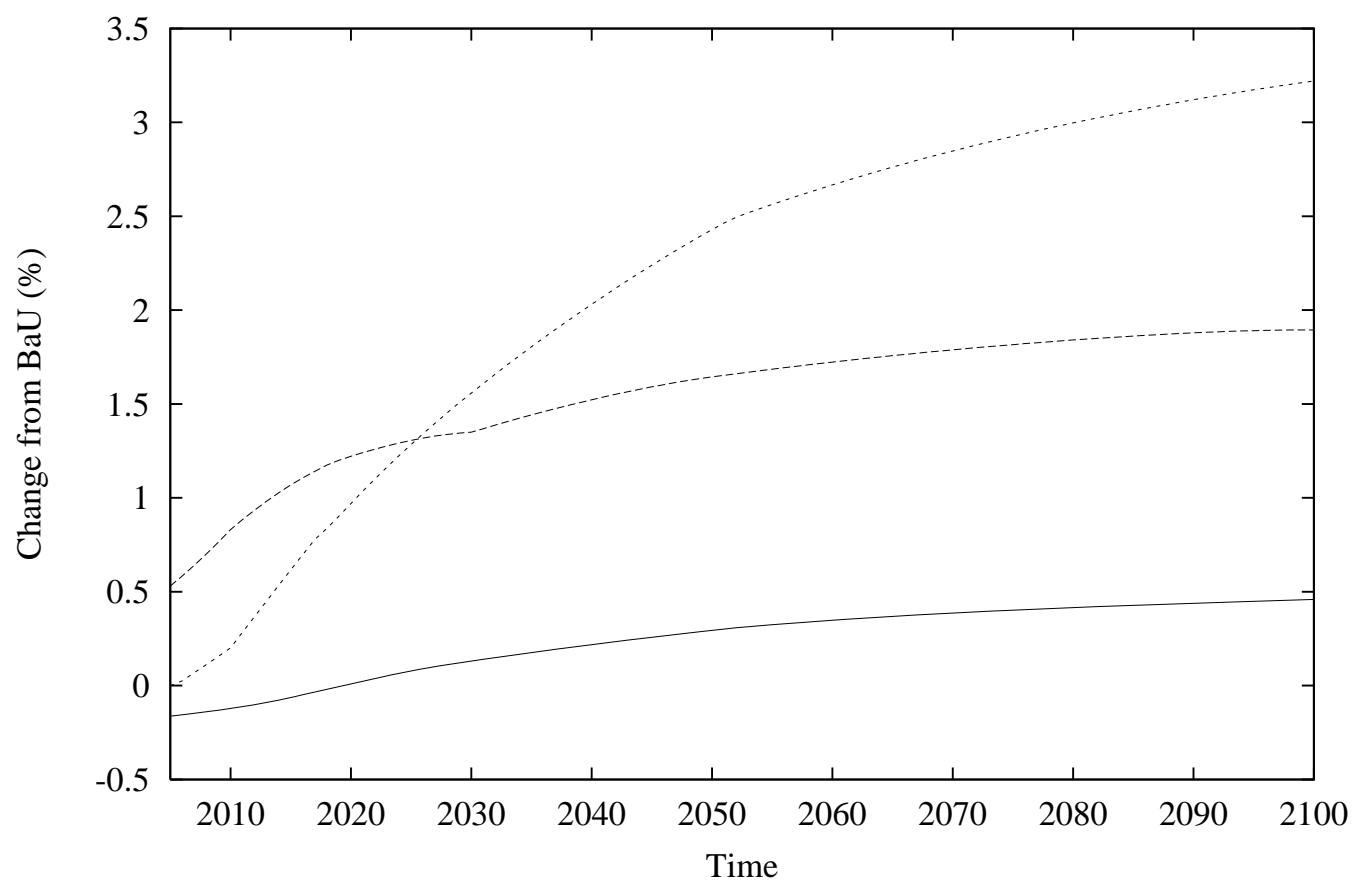

Consumption

Investment

Electricity

Figure 6: Dynamic Impacts of Green Quotas 


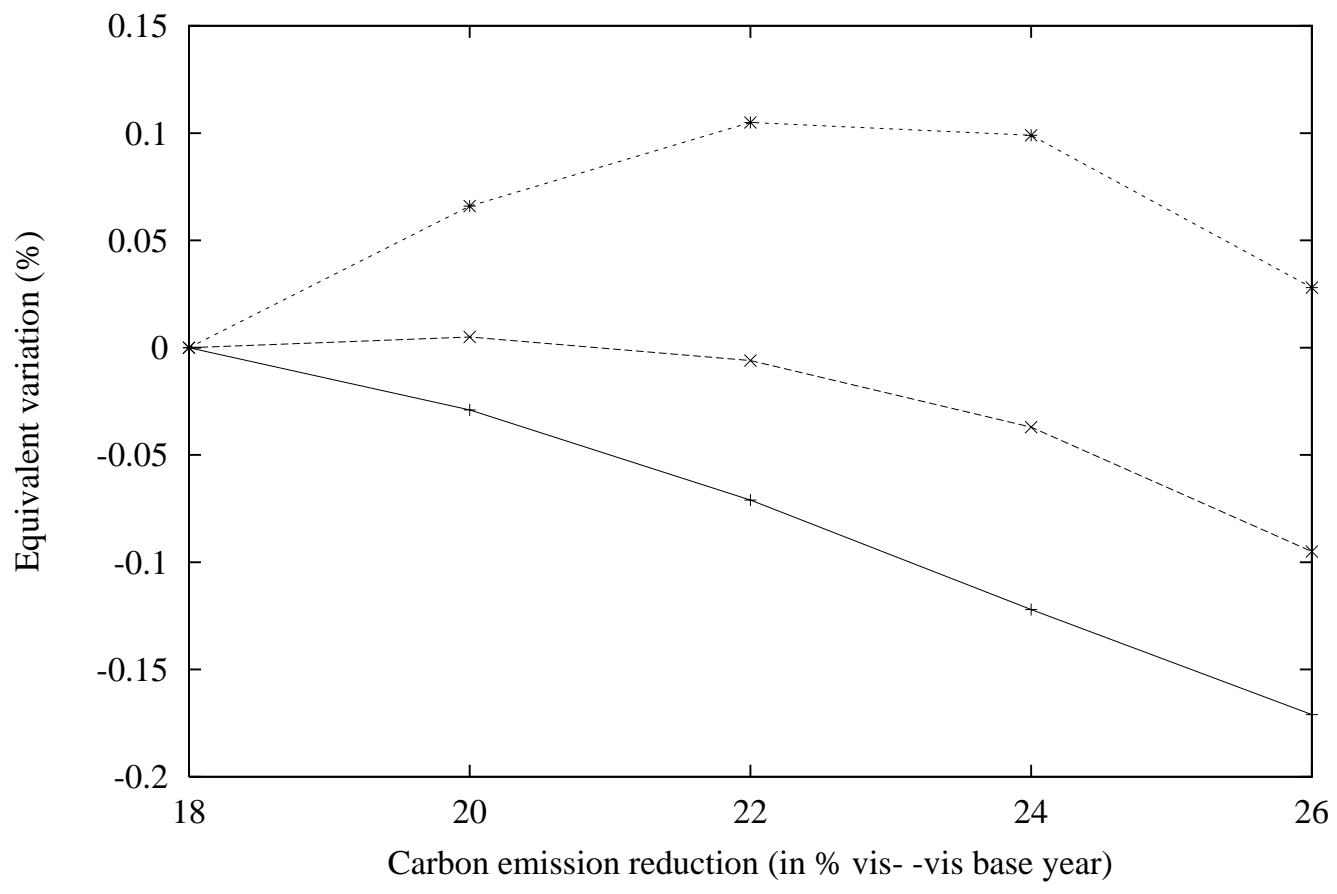

LS - $\quad$ TC $---* \cdots \quad$ TL $\cdots \cdots \cdots$

Figure 7: Static Welfare Effects of Environmental Tax Reforms 


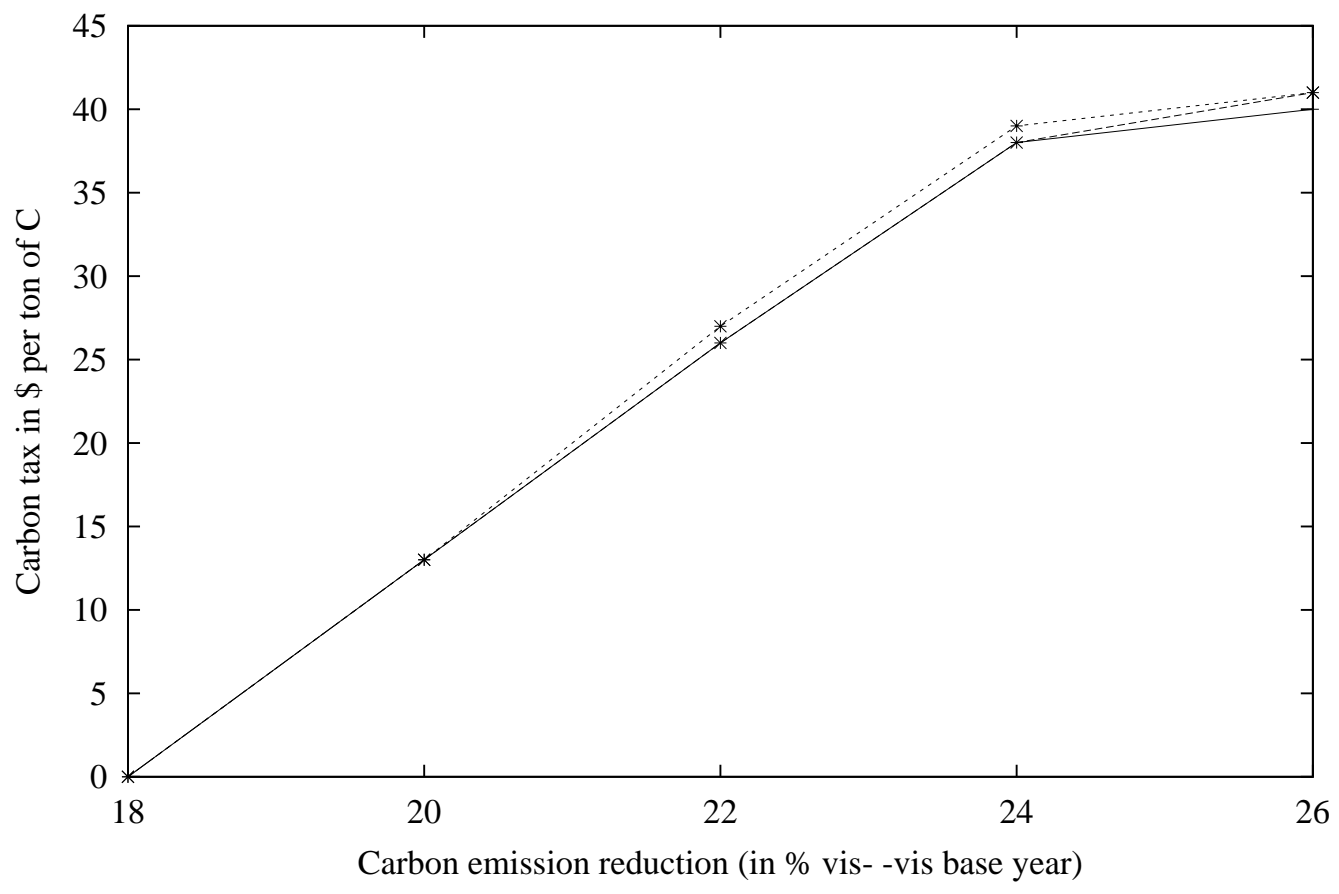

$\mathrm{LS} \longrightarrow \mathrm{TC}-\mathrm{TC}_{--\cdots} \quad \mathrm{TL} \cdots \cdots$

Figure 8: Static Carbon Tax Rates of Environmental Tax Reforms 


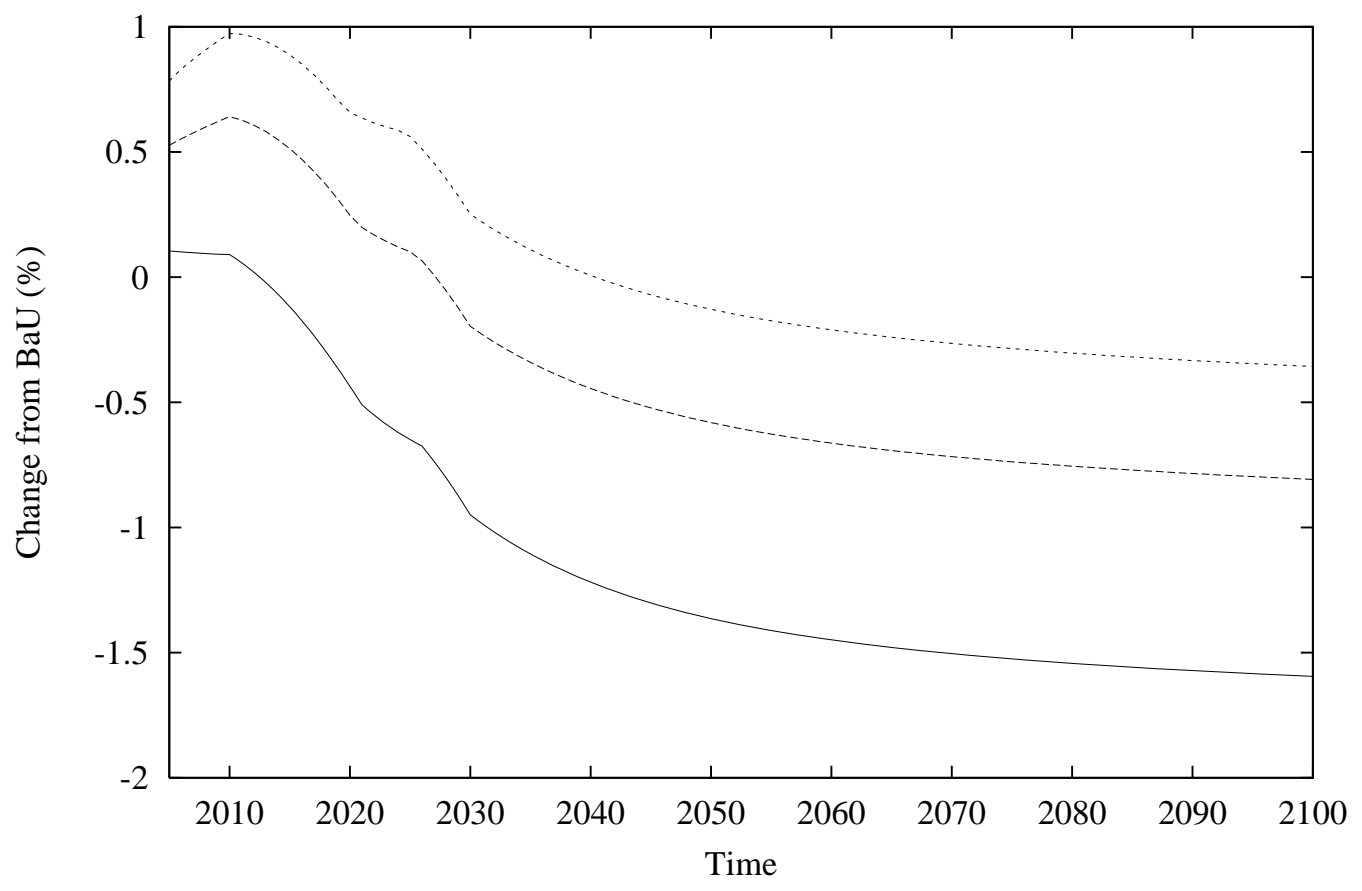

LS - TC $\cdots \cdots$

Figure 9: Dynamic Consumption Effects of Environmental Tax Reforms 